\title{
Fibrocartilaginous embolism of the spinal cord: a clinical and pathogenetic reconsideration
}

\author{
Luigi Tosi, Gianfranco Rigoli, Alberto Beltramello
}

\begin{abstract}
A 16 year old girl did a handstand for fun, returned to her feet, experienced a sudden pain in her back, and became progressively paraplegic within 30 hours. MRI showed lumbar cord swelling, multiple Schmorl's nodes, a collapsed T11-T12 disc space, and intraspongious disc prolapse into the T12 vertebral body. These findings, related to the initial manoeuvre, suggested that an acute vertical disc herniation could have occurred as the first step in a process leading to spinal cord infarction due to fibrocartilaginous emboli from the nucleus pulposus of the intervertebral disc. The medical literature so far reports 32 cases of fibrocartilaginous embolism (FCE) of the spinal cord, all at necropsy, with the exception of one histologically demonstrated in a living patient. A clinical diagnosis of FCE would be desirable for many important reasons, but was never made. This causes severe limitations in the knowledge of the disease and precludes any therapeutic possibility. On the basis of the clinical features and findings in the present case, compared with data from the reported cases, a first attempt is made to identify the clinical context within which new information obtainable through MRI examination can lead to a reliable clinical
\end{abstract}

diagnosis of FCE. The vexed question of the pathogenesis has been reviewed. An increased intraosseous pressure within the vertebral body, due to acute vertical disc herniation, seems to offer a consistent pathogenetic explanation and some therapeutic prospects.

\section{$(尹$ Neurol Neurosurg Psychiatry 1996;60:55-60)}

Keywords: fibrocartilaginous embolism; spinal cord infarction; intervertebral disc; magnetic resonance imaging

In 1961 Naiman et al ${ }^{1}$ reported the case of a 15 year old boy who was thrust backward to the floor during a basketball game, rose and completed the game, then complained of a sudden epigastric pain spreading to his back, neck, and shoulders. He became progressively tetraplegic with breathing difficulties and died three hours later. At necropsy, the lethal lesion proved to be multiple fibrocartilaginous emboli from the nucleus pulposus of the intervertebral disc to the upper cervical cord and adjacent brainstem. Since then, 31 other cases of fibrocartilaginous embolism (FCE) of the spinal cord have been reported (table). All were fatal, with the exception of one patient with rapidly evolving paraplegia, in whom laminectomies were performed and fibrocarti-

Summary of reported cases of fibrocartilaginous embolism of the spinal cord vessels

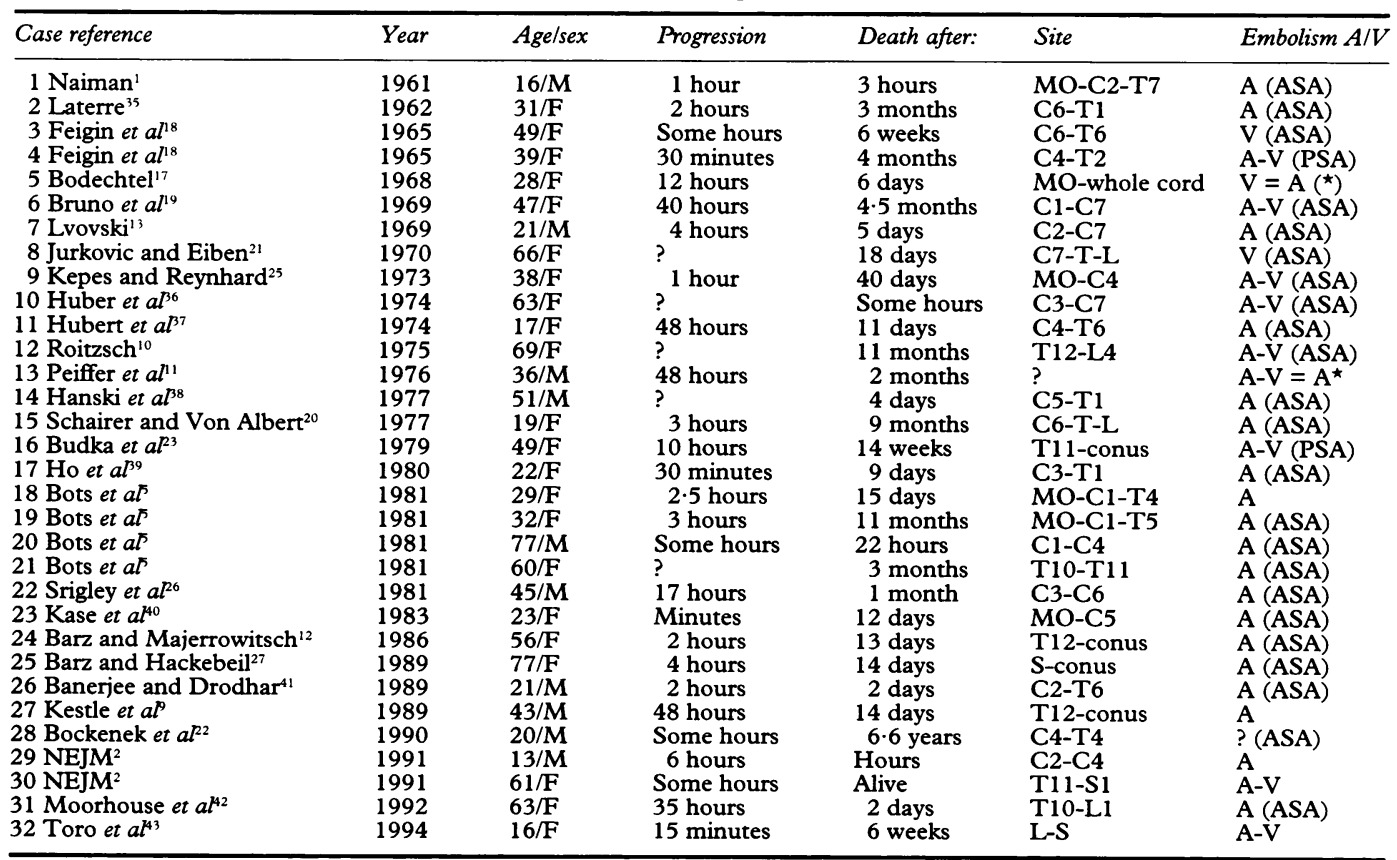

Ospedale "Sacro Cuore", Negrar, Verona, Italy L Tosi G Rigoli

Istituto di Radiologia, Università di Verona, Italy

A Beltramello

Correspondence to:

Dr Luigi Tosi, Servizio di

Neurologia, Ospedale "Sacro Cuore", 37024 Negrar, Verona, Italy.

Received 20 March 1995 and in revised form

Accepted 6 September 1995 Progression $=$ time from sudden pain at onset to maximum neurological deficit; Embolism $\mathrm{A} / \mathrm{V}=$ emboli in arteries, veins, or
both; distinction between $\mathrm{A}$ and $\mathrm{V}$ was not always clear; $\mathrm{MO}=$ medulla oblongata; $\mathrm{C}=$ cervical; $\mathrm{T}=$ thoracic; $\mathrm{L}=$ lumbar; $\mathrm{S}=$ sacral; Conus = conus medullaris; ASA = territory of the anterior spinal artery; PSA $=$ territory of the posterior spinal arteries; ? =
not given; *exclusively arterial on re-examination by Schairer and Von Albert. 20 
laginous emboli were histologically demonstrated in the vessels of the spinal cord. ${ }^{2}$ Only one fatal case of systemic FCE with cerebral and myocardial infarction has been reported. ${ }^{3}$ So far the diagnosis of FCE has only been from histology. There are, however, important reasons for aiming at a clinical diagnosis. The disease is probably not as rare in humans as it seems. In animals, and especially in dogs, it is frequent enough to appear in a veterinary review under the heading "common neurologic problems." Many patients probably survive with no definite diagnosis or are classed as something else-for example, as acute transverse myelitis, acute ischaemic or necrotising myelopathy, anterior spinal artery syndrome, Guillain-Barrè syndrome, or spinal cord injury without radiographic abnormalities. The relative frequency of the involved spinal cord level is surely distorted. Cervical localisation is apparently more frequent because fatal cases mainly result from the involvement of the cervical cord and adjacent medulla oblongata, whereas lumbar localisation, leading to death only after complications, should be more frequent, as in any other diseases of the intervertebral discs. The number of pathological diagnoses is certainly reduced in the absence of clinical suggestion. The histological diagnosis of FCE requires multiple specific stains of many sections and careful identification of the emboli in the regional vasculature, a non-routine examination that would be carried out appropriately only on clinical indication. All this is attested by the experience of Bots et al ${ }^{5}$ : in their second and third cases, the diagnosis was suspected before death on the basis of previous experience, and a fourth case resulted through re-examination of a specimen used in a teaching programme under the diagnosis "acute transverse myelopathy." A better understanding of this peculiar type of embolism "must await a firm clinical diagnosis in a living patient." In fact, the study of the pathogenesis is impoverished without antemortem suggestion. When the histological diagnosis on fixed specimens arrives, after some weeks, the time for a profitable investiga-

Figure 1 Day 3 MRI of the lumbar region. The $T 1$ weighted sequence (left) shows enlargement of the distal cord and conus, without evidence of enhancement. The T2 weighted sequence (right) shows increased signal within the cord from T11 to $L 1$ vertebral level. (By kind permission of the Service of Neuroradiology, City Hospital, Verona.) tion of the vertebral column is over. Moreover, the clinical presentation of FCE is that of a sudden pain in the back or the neck, followed by a progression of signs and symptoms indicating a spinal stroke in evolution. A therapeutic intervention could be possible, provided that a clinical diagnosis is made. On the basis of the clinical features and findings of the reported case compared with data from the histologically demonstrated cases, a first attempt is made here to identify the clinical setting within which new information obtainable through MRI examination can lead to a reliable clinical diagnosis of FCE of the spinal cord.

\section{Case report}

A 16 year old girl was in good health on the afternoon of 7 May 1994, when she cycled to her grandmother's house to play with her cousins. She was active and sport loving, her only complaint being some back pain after exertion. She did a handstand for fun, to show off. When she got up, she "felt something snap" and experienced a sudden pain in her back. She cycled home and rested for half an hour but the back pain persisted, radiating down to her upper thighs. Walking became more and more difficult; pain radiated first to the left and then to the right leg, while her left foot weakened. At $1100 \mathrm{pm}$ she was admitted to a neurological department. Flexion and extension of the foot were abolished on the left and weak on the right, whereas the strength in the proximal segments was preserved. Knee jerks were normal, ankle jerks were absent, and the plantar responses were unobtainable. Touch, pain, and temperature appreciation were reduced on the left leg below the knee, but proprioception was preserved. During the night the back pain persisted and micturition became difficult. Next morning she could stand only with support. Knee jerks were also abolished and touch, pain, and temperature sensation were reduced bilaterally below the knee. In the afternoon the weakness progressed to paralysis and there was urinary

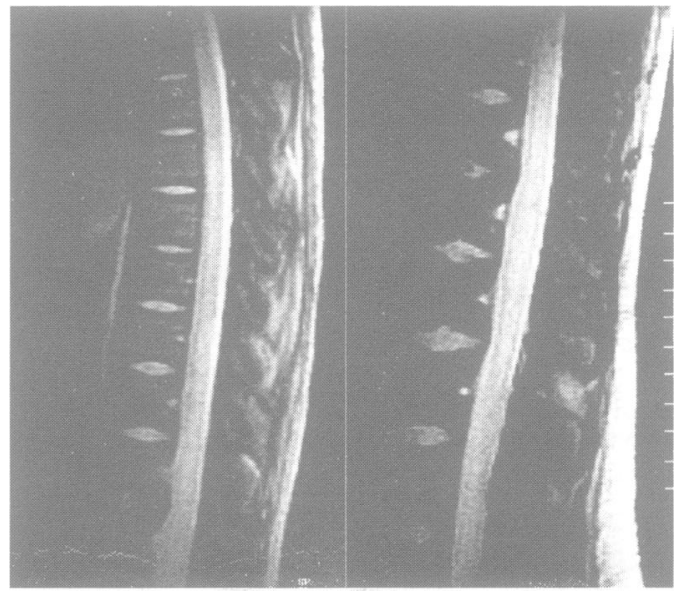

Figure 2 Day $10 \mathrm{MRI}$ of the thoracic (left) and lumbar region (right). The T2 sequences show extension of signal hyperintensity within the cord to the mid-dorsal region. Conus enlargement is more evident. (By kind permission of the Service of Neuroradiology, City Hospital, Verona.) 
Figure 3 Follow up MRI study five months later. In the $T 1$ weighted image (left) pronounced atrophy of the epiconus is evident maximally at the T11-T12 vertebral level, and the $T 2$ image (right) shows signal hyperintensity within the atrophic cord. In all the MRI studies, the T11-T12 intervertebral disc space appeared very narrow with a vanishing nucleus pulposus signal and very large Schmorl's nodes at the opposite end plates.
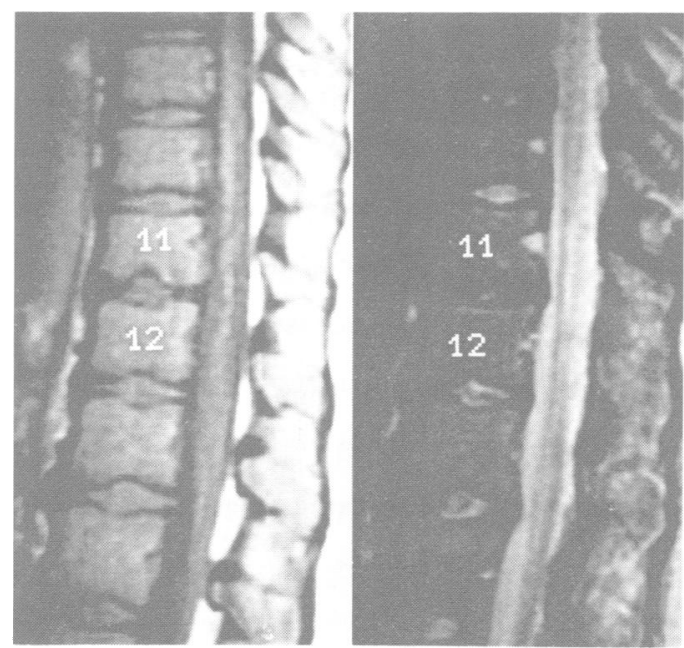

retention with complete sensory loss below T12. Plain spinal radiographs showed Schmorl's nodes in the thoracolumbar region but no evidence of fracture. Her CSF was normal. She was transferred to a neurosurgical department. Neurological examination confirmed full paraplegia with flaccid areflexic lower extremities and absent pinprick sensation below T12; proprioception was also abolished. An MRI study 48 hours after onset showed enlargement of the distal cord and conus medullaris, with a non-enhancing area of increased signal intensity on the $\mathrm{T} 2$ weighted sequences (fig 1). Conventional and computed myelography were non-contributory. Selective spinal angiography showed a patent great radicular artery arising at the T8 vertebral level on the left but no evidence of dissecting aneurysm or vascular malforma-
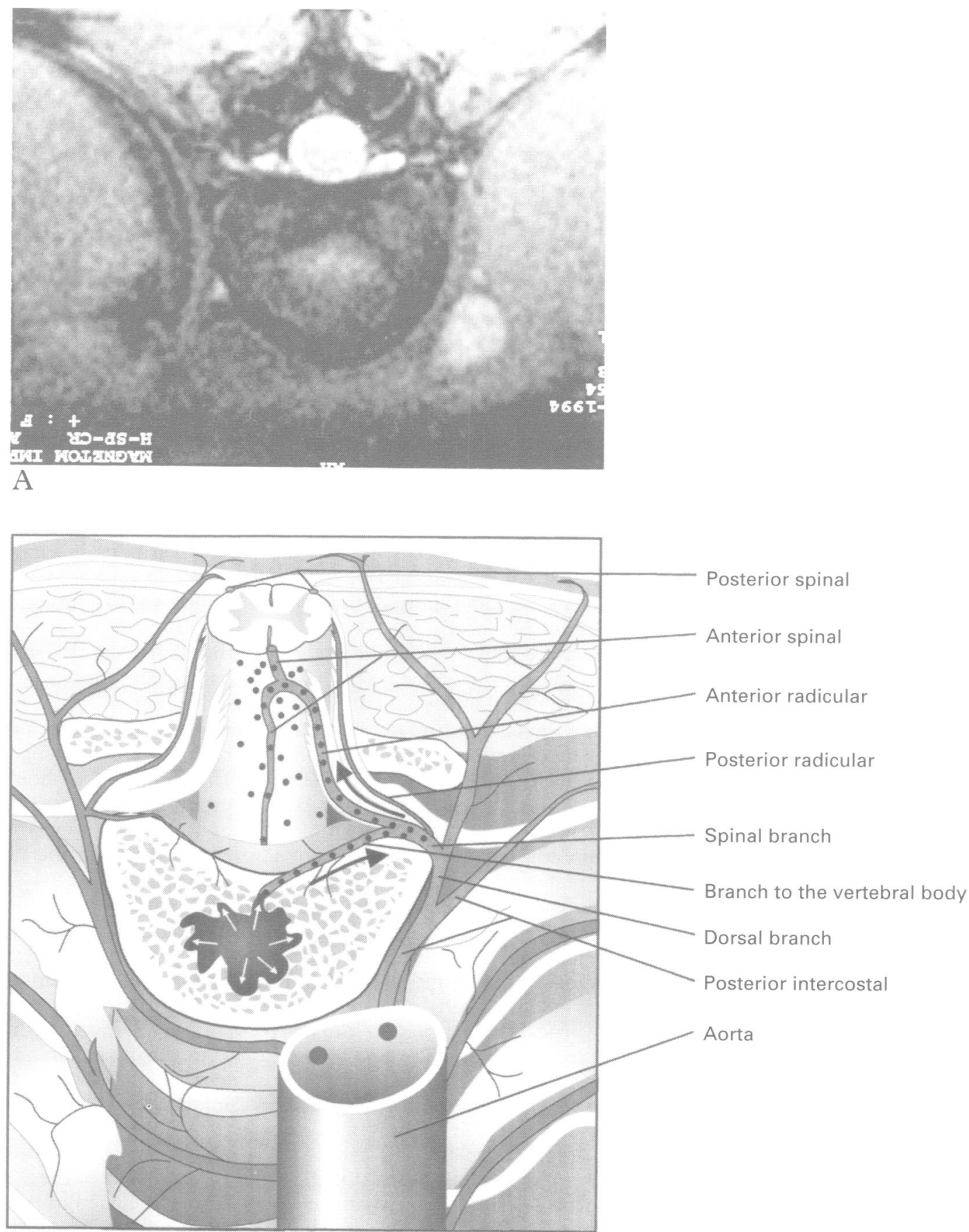

Figure 4 (A) Day 10 MRI. Cross section of the T12 vertebral body shows prolapse of disc material into the vertebral body.

(B) Schematic drawing inspired by Netter. ${ }^{14}$

Nucleus pulposus material prolapsed under pressure into the cancellous bone of the vertebral body causes retrograde arterial embolisation to several segments of the spinal cord, mainly in the territory of the anterior spinal artery. 
tions. Brain and cervical region MRI was normal. Sensory conduction velocity was normal whereas motor conduction velocity was unobtainable and EMG showed complete denervation in the lower limbs. No abnormalities were found in the upper limbs. At a control MRI on day 10 (fig 2), the area of increased signal intensity on $\mathrm{T} 2$ in the enlarged segments had extended and other poorly defined areas of increased signal intensity appeared in the middorsal region. Examination of CSF showed an increase of protein content to $1.43 \mathrm{~g} / \mathrm{l}$. An extensive investigation of blood and CSF for metabolic, infectious, and immunological changes was negative. Paraplegia remained complete. A follow up MRI study five months later (fig 3) showed pronounced atrophy of the lower spinal cord. As in the first MRI study, the T11-T12 intervertebral disc space seemed very narrow, and cross sections showed intraspongious disc material in the T12 vertebral body (fig 4A). Five very large Schmorl's nodes were present in the thoracolumbar region.

\section{Discussion}

The serial MRI studies showed that this patient had an infarction of the lower spinal cord and conus. Cord swelling and increased T2 signal in the acute phase, atrophy, and dyshomogeneous signal intensity in the chronic phase are typical findings of infarction, in the absence of cord compression and of any other known neurological disease. ${ }^{6-8}$ In our patient the MRI study also showed multiple Schmorl's nodes, a collapsed T11-T12 intervertebral disc, and intraspongious disc prolapse into the T12 vertebral body, suggesting that an acute vertical disc herniation could have occurred. In the pathologically established cases of FCE, radiological assessment with plain spine radiographs, myelography, and CT has been unrevealing. Two studies used MRI. Kestle et al reported that MRI showed multiple Schmorl's nodes but no abnormalities of the spinal cord, and was considered of no diagnostic value. Serial MRI examination in the only living patient ${ }^{2}$ showed an evolution of spinal cord infarction similar to ours, with the difference of an initial slight haemorrhagic component. A later high T2 signal intensity within the T11 vertebral body was considered to be "a focal pathologic process within the bony marrow cavity." Buckled end plates and disc space reduction appear in the images but were not discussed.

In our opinion an MRI finding of cord swelling associated with a collapsed disc space at the appropriate level, in a corresponding clinical setting, should strongly suggest, if not prove, that a vertical disc herniation into a vertebral body had occurred as the first step of a process leading to FCE. The same criteria are considered to be valid for clinical diagnosis of FCE in veterinary medicine. ${ }^{4}$ For the assessment of the appropriate clinical setting the main features of the 32 so far histologically demonstrated cases have been examined and summarised in the table.
The patients range in age from 13 to 77 (mean 39) years, with a bimodal distribution: the first peak occurs in adolescence through young adulthood (mean 22 years), and the second in late middle age (mean 60 years). There is a net predominance of women, 22 of 32 cases.

\section{Precipitating factors}

A close temporal relation with a significant minor trauma comparable with our case occurred in six cases: falls, ${ }^{1}{ }^{1011}$ a jump with a drop of $80 \mathrm{~cm},{ }^{12}$ a forced head movement during a brawl, ${ }^{13}$ and somersaults. ${ }^{2}$ In five patients symptoms appeared on awakening, in others after physical effort or Valsalva-like manoeuvres. Low back pain was present in the history of several patients; vehicle accident, vertebral body fracture, lumbar disc surgery, pregnancy, oral contraceptive, or corticosteroid treatment occurred in the history of one patient each. No relevant precipitating factor was reported in most cases. The hypothesis of a vertical disc herniation makes the discussion about precipitating factors very similar to that regarding posterior disc herniation, where only in a minority of cases can a clear time relation be established between minor trauma or physical effort and onset of symptoms.

\section{Clinical features}

In the clinical course of the histologically established cases of FCE, three main characteristics distinguishing it from thrombotic or embolic spinal cord infarction could be identified. The first was the sudden severe pain at onset, localised in the neck and the interscapular region in cases with cervical cord involvement, and in the back in cases with lumbar cord involvement. Extension of the pain to the chest or abdomen occurred in some cases, with the character of a somatic referred pain. In thrombotic or embolic infarction, a sudden pain can be absent and is hardly the leading symptom. ${ }^{14}$ If present, it has a radicular or girdle distribution. ${ }^{1516}$ As a second characteristic, the neurological signs and symptoms in FCE had a free interval and a progression in time indicating a "spinal stroke in evolution." The interval from onset of pain to maximum neurological deficit ranged when definable from 15 minutes to 48 hours (table). In thrombotic or embolic infarction numbness and weakness of the limbs appear at onset, in most cases abruptly and at the same time as pain, if present. ${ }^{14-16}$ As a third characteristic, no case of FCE showed a significant improvement of the neurological deficit, whereas most patients with thrombotic or embolic infarction show substantial recovery, so that the favourable course contributes to the final diagnosis. ${ }^{14-16} \mathrm{~A}$ further difference is the higher prevalence of young women with FCE and of late middle aged or older men with thrombotic or embolic infarction.

\section{Neuropathological lesions (table)}

In $22(69 \%)$ of the 32 reported cases, embolisation occurred in the cervical cord, extending in some patients to the lower medulla oblon- 
gata and to the upper thoracic segments. In nine patients the lesion site was in the lumbar region, usually extending to the low thoracic cord or to the sacral segments. In one instance the whole cord was affected. ${ }^{17}$ High cervical and medulla oblongata lesions were associated with respiratory involvement and short survival times. In the lumbar localisation death was determined by secondary complications (pulmonary embolism, sepsis), and the only patient diagnosed by surgical biopsy remained alive. Location in the vascular bed was a vexed question. Histological differentiation of arteries and veins was sometimes uncertain; authors had doubts on their own identification $^{1819}$ and correction of a previous identification by others ${ }^{20}$ occurred. As a final assessment, emboli were exclusively arterial in 21 cases, both arterial and venous in eight cases, and venous (with doubts) in two cases, ${ }^{1821}$ whereas one case remained undefined. ${ }^{22}$ The infarction was of the ischaemic type; in most cases it was in the territory of the anterior spinal artery, in two cases in the area of the posterior spinal artery, ${ }^{1823}$ and in some cases complete transverse ischaemic myelopathy occurred.

\section{PATHOGENESIS}

The finding of fibrocartilage within the spinal vessels is intriguing. There is general agreement that the emboli originate from the intervertebral disc, but the mechanism whereby disc fragments enter the vessels is difficult to understand. Naiman et $a l^{1}$ speculated that an intervertebral disc had ruptured laterally, causing damage to an adjacent radicular artery with entrance of disc fragments into the arterial circulation. The main objection to this is that local haemorrhages would be almost inevitable by a contemporary rupture of disc and radicular artery, and they have never been found. An alternative hypothesis was that high axial loading had caused increased pressure within an abnormally vascularised but not ruptured disc, with injection of semifluid nucleus pulposus material into small arteries and retrograde spread to a radicular artery. The intervertebral disc is usually avascular but vessels may persist until adolescence or reappear later in life in degenerated discs. The main objection is the lack of an adequate precipitating event in most cases. Feigin et $a l^{18}$ first drew attention to masses of fibrocartilage in their cases, often found within the bone marrow of the vertebral bodies as Schmorl's nodes. They are thought to be a prolapse of disc material into the vertebral body through defects in the end plates (disc/marrow contacts. ${ }^{24}$ ) Disc material may arrive in this way to sinusoids and venules of the marrow, and from these readily drain as emboli through the basivertebral vein to the epidural plexuses and then into small branches of the pulmonary artery, as in fat embolism. If in the valveless perispinal veins the pressure become transiently high, as in any Valsalvalike condition, a retrograde flow may push emboli backward into the veins of the spinal cord. Arteriovenous anastomoses would explain the passage to the arterial side.
Fibrocartilage within the marrow spaces was documented in other cases. ${ }^{12} 252627$ In the study of Srigley et $a l^{-6}$ the $\mathrm{C} 2-\mathrm{C} 3$ vertebral bodies were directly apposed, whereas disc tissue was displaced into the C3 vertebral body through microfractures in the endplate and fragments were found as emboli in the sinusoids of the bony marrow. Barz found in both reported cases $^{1227}$ fresh intrusion of fibrocartilage, surrounded by granulation tissue, in the marrow of one vertebral body. Emboli were found in sinusoids and veins and also in arteries, and these were considered to be the site of entry of disc material into the vascular system. From there emboli could be forced by retrograde flow into the segmental arteries to reach the spinal cord by anterograde flow. The vis a tergo should be supplied by high intradiscal pressure. Barz's pathogenetic hypothesis, pointing at the arteries of the vertebral body as entry site of the emboli, allows a coherent explanation of the subsequent events, only his assumption of high intradiscal pressure as source of the vis a tergo being unconvincing. The intradiscal pressure must abruptly decrease after nucleus pulposus extrusion and could hardly support the progression of symptoms. The source of the propulsive force is more likely to be increased intraosseous pressure due to forced intrusion of disc material into the marrow spaces of a non-dilatable vertebral body. A cadaveric experiment by Yoganandan et $a l^{28}$ reproduced this mechanism. A functional unit consisting of two lumbar vertebrae with the interposed disc was excised. Radio-opaque dye was injected into the nucleus pulposus and its movements were monitored under fluoroscopy. Transducers were inserted into the vertebrae to record intraosseous pressure. Progressive loading was applied until injury occurred. Before reaching the limiting load and before any radiologically demonstrable fracture, one of the endplates buckled and contrast medium moved into the spongiosa, while the intraosseous pressure rapidly increased in comparison with the pressure in the vertebral body with intact end plates.

Acute symptomatic intraosseous disc herniation without involvement of the spinal cord has been demonstrated on radiographs after bony reaction; $;^{29}$ 30 $\mathrm{MRI}$ was more sensitive showing prompt loss of signal intensity in the affected intervertebral disc space, confirmed later by changes in the underlying cancellous bone. ${ }^{31} 32$ Acute herniation into a vertebral body must lead to increased intraosseous pressure, according to Yoganandan et al. ${ }^{28} \mathrm{At}$ lower levels of increase in pressure, disc material remains in situ or may be pushed into the venous system with subclinical embolisation to the lungs, this being the usual outcome. A retrograde flow of emboli to the spinal veins may remain asymptomatic as well. ${ }^{18}$ At unusually high pressures, disc material can be forced not only into the veins but also into the arteries of the vertebral body, as shown by Barz ${ }^{12}$ and Barz and Hackebeil. ${ }^{27}$ Only in cases where the intraosseous pressure is persistently high enough to cause a lasting arterial reversal flow 
can a progressive embolisation of the spinal cord occur (fig 4B). This condition may account for the rarity of the event. The infarction is due to embolic arterial occlusion, whereas venous emboli, mostly asymptomatic, are an accessory finding. This explains the fact that the spinal infarction in FCE is always of the arterial type, even when both arterial and venous emboli are present. The involvement of the territory of the anterior spinal artery in most cases, and of several spinal segments in each case, is explained by the anatomy of the spinal vessels (fig 4B). An arterial microembolisation also explains the clinical course of FCE by comparison with thrombotic or embolic infarction. The spinal cord is well protected by extensive arterial anastomoses and the occlusion of larger arterial branches may cause an abrupt onset of signs and symptoms but allows a functional recovery in most cases. The progressive occlusion of the end flow system of the intrinsic spinal arterioles must cause definitive damage. Finally, the envisaged pathogenetic mechanism allows some therapeutic prospects. Measurements of intraosseous vertebral pressure can be performed in vivo ${ }^{33}$ and devices for its reduction could be found as a way to stop the progression of embolism. Drugs with a lytic effect on fibrocartilaginous emboli could also be conceived. Of course, "a firm clinical diagnosis" is needed first. An obstacle may be the tendency to consider FCE as an odd disease, a "lusus naturae", which it is not. After the first description in a human, FCE was described in the dog. ${ }^{3 .}$ Since then there have been numerous reports of this condition in dogs, as well as isolated cases in horses, pigs, cats, and lambs. In the dog the mechanism cannot be formation of Schmorl's nodes, these being almost unknown in relation to the different loading pattern of quadruped posture; a direct passage of disc material into the vessels is the most accepted explanation. In any case, the comparative pathology demonstrates that FCE is a pathological pattern common to various species of vertebrates, with differences reflecting the course of evolution.

1 Naiman JL, Donohue WL, Prichard JS. Fatal nucleus pulposus embolism of spinal cord after trauma. Neurolog 1961;11:83-7.

2 Case records of the Massachusetts General Hospital. N Engl Med 1991;324:322-32.

3 Toro G, Navarro-Roman L, Roman GG, et al. Acute ischemic stroke from fibro-cartilaginous embolism to the middle cerebral artery. Stroke 1993;24:738-40.

4 Cook JR Jr. Fibrocartilaginous embolism. Vet Clin North Am Small Anim Pract 1988;18:581-92.

5 Bots GT, Wattendorff AR, Buruma OJS, Roos RAC, Endt LJ. Acute myelopathy caused by fibrocartilaginous emboli. LJ. Acute myelopathy caused
Neurology 1981;31:1250-6.

6 Yuh WTC, Marsh EE, Wang AK, et al. MRI of spinal cord and vertebral body infarction. A7NR Am 7 Neuroradiol and vertebral body

7 Kume A, Yoneyama S, Takahashi A, Watanabe H. MRI of anterior spinal artery syndrome. $\mathcal{f}$ Neurol Neurosur Psychiatry 1992;55:838-40.

8 Hirono H, Yamadori A, Komiyama M, et al. MRI of spontaneous cord infarction: serial changes in gadolinium-DTPA enhancement. Neuroradiology 1992;34:95-7.

9 Kestle JRW, Resch L, Tator CH, Kucharczyr W Intervertebral disc embolisation resulting in spinal cord infarction. F Neurosurg 1989;71:938-41.

10 Roitzsch E. Die Faserknorpelembolie der Rückenmarksgefäße: eine seltene Ursache der Myelomalazie. Zentralblatt für Allgemeine Pathologie und Pathologisch Anatomi $1975 ; 119: 100-3$
11 Peiffer J, Wenig Ch, Mäusle E. Akutes Querschnittssyndrom durch Embolien von Nucleus-pulposus-Gewebe. Dtsch Med Wochenschr 1976;101:583-6.

12 Barz H, Majerrowitsch B. Myelomalazie durch Embolie von Bandscheibengewebe in Wirbelkörper-und Rückenmarksarterien. Zentralblatt für Allgemeine Pathologic und Pathologische Anatomie 1986;131:119-25.

13 Lvovskiy AM. Embolia sosudow spinnogo mozga tkani mezpozwonkowo diska. (embolism of spinal vessels by tissu of the intervertebral discs). $Z$ Newropath Psikchiatr Korsako 1969;8:1151-7.

14 Silver JR, Buxton PH. Spinal Stroke. Brain 1974;97:539-50,

15 Sandson TA, Friedman JH. Spinal cord infarction. Report of 8 cases and review of the literature. Medicine 1989;68 $282-92$

16 Monteiro L, Leite I, Almedia Pinto J, Stocker A. Spontaneous thoracolumbar spinal cord infarction: report of six cases. Acta Neurol Scand 1992;86:563-6.

17 Bodechtel G. Uber differentialdiagnostische Schwierigkeiten auf den Grenzgebieten der inneren Medizin zur Neurologie. Münchener Medicinische Wochenschrift 1968; 110:969-80

18 Feigin I, Popoff N, Adachi M. Fibrocartilagenous venou emboli to the spinal cord with necrotic myelopathy. Neuropathol Exp Neurol 1965;24:63-74

19 Bruno MS, Ober WB, Flynn JT, Karpas CM, Shapiro DE, Feigin I. Sudden onset of severe chest pain and paralysis. NY State f Med 1969;69:446-54.

20 Schairer E, Von Albert HH. Aufsteigende Querschnittssymptomatick bei embolischem Verschluss der Rückenmarksarterien durch Bandscheinbengewebc. Münchener Medicinische Wochenschrift 1977;119:1433 6 .

21 Jurkovic I, Eiben E. Fatal myelomalacia caused by massive fibrocartilaginous venous emboli from nucleus pulposus. Acta Neuropathol (Berlin) 1970;15:284-7.

22 Bockenek WL Bach JR, Alba SA, Cravioto HM Fibrocartilaginous emboli to the spinal cord: a case report. Arch Phys Med Rehabil 1990;71:754-7.

23 Budka H, Perneczky A, Pusch S. Bandscheibengewebsembolien in Spinalgefäßen als Ursache von Myelomalazien vorwiegend in Spinalis-posteriorVersorgungsgebieten. Wien Klin Wochenschr 1979;91: 578-83.

$24 \mathrm{McF}$ adden KD, Taylor JR. End-plate lesions of the lumbar spine. Spine 1989;14:867-9.

25 Kepes JJ, Reynhard JD. Infarction of spinal cord and medulla oblongata caused by fibrocartilaginous emboli. Report of a case. Virchows Arch Pathol Anat Histopathol 1973;361: $185-93$.

26 Srigley JR, Lambert CD, Bilbao JM, Pritzker KPH. Spinal cord infarction secondary to intervertebral disc embolism. Ann Neurol 1981:9:296-301.

27 Barz H, Hackebeil C. Knorpelgewebsembolie als Ursache einer Myelomalazie. Kasuistik und Literaturübersicht. $D_{e}$ Pathologe 1989;10:300-5.

28 Yoganandan N, Larson SJ, Gallagher M, et al. Correlation of microtrauma in the spine with intraosseous pressure. Spin 1994;19:435-40.

29 McCall IW, Park WM, O'Brien JP, Seal V. Acute traumatic intraosseous disc herniation. Spine 1985;10:134-7.

30 Lipson SJ, Fox DA, Sosman IL. Symptomatic intervertebra disc herniation (Schmorl's node) in the cervical spine. Am Rheum Dis 1985;44:857-9.

31 Kornberg M. MRI diagnosis of traumatic Schmorl's node. A case report. Spine 1988;13:934-5.

32 Walters $\mathrm{G}$, Coumans JM, Akins CM, Ragland RL. Magnetic resonance imaging of acute symptomatic Schmorl's node formation. Pediatric Emergency Care 1991;7:294-6.

33 Essens SI, Moro JK. Intraosseous vertebral body pressure. Spine 1992;17:S155-9.

34 Griffiths IR. Spinal cord infarction due to emboli arising from the intervertebral disc in the dog. F Comp Pathol 1973;83: 225-32

35 Laterre EC. Syndrome spinal anterieur par embolies multiples de tissu fibro-cartilagineux. Rev Neurol (Paris) 1962 106:685-90.

36 Hubert JP, Ectos M, Ketelbanth-Balasse P, FlammentDurand J. Fibrocartilaginous venous and arterial emboli from the nucleus pulposus in the anterior spinal system. Eur Neurol 1974;1:164-71.

37 Hubert JP, Retif J, Brihaye J, Flament-Durand J. Infartu medullaire par emboles de noyau pulpeux; nouvelle obsermedullaire par emboles de noyau pulpeux; nouvelle obser-
vation anatomoclinique. Acta Neurol Belg 1974;74: vation anat $297-303$.

38 Hanski W, Rydzewska M, Fundowicz R. Zatory naczyn rdzeria Kregowego tkanka jadra miazdzystego. (emboli of spinal cord vessels with the tissue of nucleus pulposus) Neuropatol Pol 1977;15:479-90.

39 Ho KL, Gorrell JM, Hayden MT. Fatal spinal cord infarction caused by fibrocartilaginous embolisation of the anterio spinal artery. Hum Pathol 1980;11:471-5.

40 Kase CS, Varakis JN, Stafford JR, Mohr JP. Media medullary infarction from fibrocartilaginous embolism to the anterior spinal artery. Stroke 1983;14:413-8.

41 Banerjee AK, Deodhar SD. Cartilage embolism of spina cord [letter]. F Neurol Neurosurg Psychiatry 1989;52:201-2.

42 Moorhouse DF, Burke M, Keohane C, Farrell MA. Spinal cord infarction caused by cartilage embolus to the anterior spinal artery. Surg Neurol 1992;37:448-52.

43 Toro G, Roman GC, Navarro-Roman L, et al. Natural history of spinal cord infarction caused by nucleus pulposus embolism. Spine 1994;13:360-6.

44 Netter FH. Atlante di anatomia fisiologia e clinica. Sistema nervoso. Vol 7. Parte $1^{\circ}$. Basle: Ciba-Geigy, 1986:65 (tav 20). 